\title{
Myxedema Ascites: A Rare Case Report
}

\author{
FARZANA HAMID ${ }^{1}$, SYED MOOSA MA QUAIUM ${ }^{2}$, AZIZUR RAHMAN²
}

\begin{abstract}
Congenital hypothyroidism is a very common condition in developing world, but myxedema ascites is very rare in pediatric population. We report a case of 13 years old girl with congenital hypothyroidism on irregular thyroxin started on second half of infancy, presented with recurrent ascites excluding all other causes and discuss different aspects of the condition on the basis of literature review.
\end{abstract}

Key words: Hypothyroidism, Myxedema, Ascites

\section{Introduction}

Myxedema is a term used synonymously with severe hypothyroidism. It refers to deposition of mucopolysaccharides in the dermis, which results in swelling of the affected area. One manifestation of myxedema occurring in the lower limb is pretibial myxedema, although it is most often confined to the pretibial area, it may occur anywhere on the skin, especially the ankle, dorsum of the foot, knees, elbows, upper back. ${ }^{1}$ Myxedema ascites was first described in 1886 and occurs in $4 \%$ of total and less than $1 \%$ of newly diagnosed cases in adults. ${ }^{2}$ Exact incidence in pediatric patients is not clear. Severe, uncontrolled hypothyroidism can lead to accumulation of fluid in body cavities, presenting as pericardial effusion, pleural effusion and ascites. Hypothyroidism is also an uncommon cause of ascites and is seen in only one to five percent of patients with ascitis. ${ }^{3}$ Treatment of underlying hypothyroidism leads to quick clinical improvement. ${ }^{4}$

\section{Case Report}

A 13-year-old girl known case of congenital hypothyroidism on irregular thyroxin started on second half of infancy presented with swelling of both legs and abdomen for 1 month and fever for 3 days. She had similar history 4 times before within last 2 years. Her urine output was normal every time she had swelling. There was no history of abdominal pain,

1. Professor, Dept. of Paediatrics, North East Medical College, Sylhet

2. Professor, Dept. of Paediatrics, North East Medical College, Sylhet

Correspondence: Dr. Farzana Hamid, MRCPCH (UK), FCPS (Paediatrics), Professor, Department of Paediatrics, North East Medical College \& Hospital, Tel: +88 01815474442, Email: drfarzanahamid@gmail.com

Received: 18-06-2018 jaundice, abnormal stool color, breathing difficulty, recurrent infection, rash, joint pain or swelling. She attained the developmental milestones quite delayed with below average IQ. She has not yet experienced menarche with no secondary sexual characteristics. Other 2 siblings are healthy with no such family history. On examination, she had dull appearance with frontal bossing, depressed nasal bridge and dry, rough wrinkled skin. She had bipedal edema with ascites but no organomegaly and vital signs were within normal limit. There was distant heart sounds and delayed relaxation of ankle jerks. Her weight and height were below $3^{\text {rd }}$ centile.

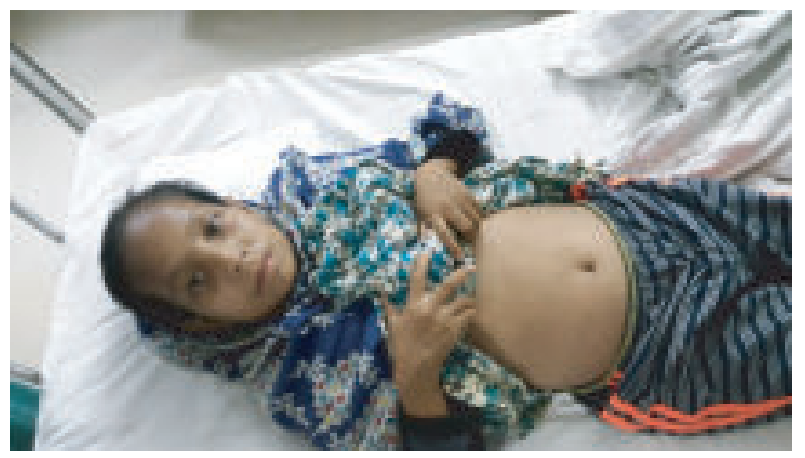

Fig.-1: Patient with myxedema ascites

Investigations revealed $\mathrm{Hb} 8.3 \mathrm{gm} / \mathrm{dl}$ with neutrophilic leukocytosis, Liver function tests were normal except Serum albumin, which was $1.9 \mathrm{gm} / \mathrm{dl}$. Urine R/M/E $\& \mathrm{C} / \mathrm{S}$ and 24 hours urinary total protein were normal. Serum cholesterol, renal function test and chest Xray were normal. Serum FT4 was low $(0.28 \mathrm{ng} / \mathrm{dl})$ along with high TSH (>100 $\mu \mathrm{lU} / \mathrm{ml})$. Serum Ascitic Albumin Gradient (SAAG) was <1.1. ECG revealed low voltage reading with mild pericardial effusion on echocardiography. USG of thyroid showed thyroid 
agenesis and bone age was delayed. The abdominal ultrasound showed normal liver parenchyma and the CT scan did not reveal any abdominal masses. AntiNuclear Antibody (ANA) was negative. So, the patient was diagnosed as myxedema ascites. She was given diuretic and thyroxin $(2 \mu \mathrm{g} / \mathrm{kg} /$ day $)$ along with supportive treatment. After 4 weeks, edema and ascites subsided completely.

\section{Discussion}

Ascites is an uncommon manifestation of hypothyroidism and rarely the primary presenting symptom. The pathophysiology of hypothyroidisminduced ascites is still not fully known. The ascites in patients with myxedema has multiple causes, including increased capillary permeability, impaired lymphatic flow, as well as accumulation of hydrophilic glycosaminoglycans in the interstitial-space. ${ }^{4}$ Hyaluronic acid (HA) is a non-sulfated glycosaminoglycan that is present throughout the body. It influences various cellular functions including motility, adhesion, proliferation, and suppression of differentiation. ${ }^{5}$-HA-degradation-is accomplished through the activity of different enzymes, most of which are localized within liver endothelial cells. ${ }^{5}$ Although normally thought of as a stimulating molecule, T3 exerts an inhibitory effect on HA synthesis. So in hypothyroid patients, low levels of circulating thyroxine (T3) stimulate HA synthesis as well as decrease the activity of enzymes responsible for $\mathrm{HA}$ degradation. ${ }^{6} \mathrm{HA}$ increases the capillary permeability resulting in extravasation of plasma proteins, specifically albumin. Therefore, analysis of ascitic fluid from patients with this condition shows exudative ascites with high protein content $(>2.5 \mathrm{~g} / \mathrm{dl}){ }^{5,6}$

A second hypothesis involves a direct hygroscopic effect caused by hyaluronic acid accumulation in the skin with resulting edema. Hyaluronic acid is only found in small quantities in patients with hypothyroidism-induced ascites and cannot be held entirely responsible for exerting the required hygroscopic effect. However, it can interact with albumin forming hyaluronic acid-albumin complexes that prevent lymphatic drainage of extravasated albumin..$^{4,7}$ Recent studies showed that low nitric oxide levels and high vascular endothelial growth factor (VEGF) levels can lead to an increase incapillary-permeability-causing extravasation of plasma proteins. A decrease in nitric oxide levels causes endothelial dysfunction due to oxidative stress, resulting in activation of inflammatory cells that release substances that increase capillary permeability. An increase in VEGF also leads to increased extravasation of plasma proteins because of abnormal capillary permeability. Levels of VEGF have been reported to be high in hypothyroid patients with a decline in level to normal values with thyroid replacement therapy. ${ }^{8}$

Ascitic fluid analysis is the key in guiding the course of investigations needed to establish the diagnosis. A high serum-ascites albumin gradient (SAAG; $>1.1 \mathrm{~g} /$ dl) suggests that the ascitic fluid is caused by portal hypertension with a $97 \%$ diagnostic accuracy. A low SAAG $(<1.1 \mathrm{~g} / \mathrm{dl})$ suggests that the ascitic fluid is not due to portal hypertension. ${ }^{3}$

Ascitic fluid in case of hypothyroidism reveals high protein $(>2.5 \mathrm{~g} / \mathrm{dl})$ and SAAG value is usually low although it may vary. Review of literature revealed 52 documented cases of myxedema ascites in adults. A very consistent finding was high total protein level $(>2.5 \mathrm{~g} / \mathrm{dl})$ in almost all cases with mean SAAG of $1.5 \mathrm{~g} / \mathrm{dl}$ with a range of $0.8-2.3 \mathrm{~g} / \mathrm{dll}^{7,9,10} \mathrm{In}$ another study, SAAG may exceed 1.1 in patients with myxedema ascites, based on a review of eight patients. ${ }^{2}$ Because so few cases have been studied about ascites in patients with myxedema, we cannot conclude that a high SAAG is a typical feature in this disease. ${ }^{11}$ Moreover, the patient reported here showed low SAAG. Multiple etiologies to our patient's anasarca were considered. She did not have a history or clinical findings suggestive of nephrotic syndrome or liver disease, tuberculosis or pancreatitis. No significant proteinuria was present to suggest a renal contribution to her presenting complaints. The abdominal ultrasound showed normal liver parenchyma and the CT scan did not reveal any abdominal masses. Hypoalbuminemia was noted to have preceded clinical presentation but malnutrition or synthetic liver dysfunction was a less likely contributor. Ascitic fluid cultures were negative for bacterial or tuberculous infections and also showed negative cytology. In the absence of other causes of ascites and in the presence of long duration of inadequately treated hypothyroidism, myxedema ascites was established as the cause of the patient's ascites as complete symptom resolution occurred after 4 weeks on levothyroxine. 


\section{Conclusion}

Hypothyroidism rarely presents with ascites but can be considered after common causes have been ruled out. Diagnostic workup should include a paracentesis with determination of the SAAG. Treatment with thyroid hormone remains an effective therapy with excellent prognosis.

\section{References}

1. Doshi DN, Blyumin ML, Kimball AB. Cutaneous manifestations of thyroid disease. Clin Dermatol. 2008; 26 (3):283-7.

2. De Castro F, Bonacini M, Walden JM, Schubert TT. Myxedema ascites: Report of two cases and review of the literature. J Clin Gastroenterol. 1991; 13:411-4.

3. Kimura R, Imaeda K, Mizuno T. Severe ascites with hypothyroidism and elevated CA125 concentration: a case report. Endocr J. 2007; 54:751-755.

4. Ji JS, Chae HS, Cho YS. Myxedema ascites: case report and literature review. J Korean Med Sci. 2006; 21:761-764.

5. R. Stern. Hyaluronan catabolism: a new metabolic pathway. Eur J Cell Biol. 2004; 83 (7): 317-325.
6. T.J. Smith, Y. Murata, A. Horwitz, L. Philipson, S.Refetoff. Regulation of glycosaminoglycan synthesis by thyroid hormone in vitro. J Clin Invest. 1982; 70 (5): 1066-1073.

7. Khalil RB, Rassi PE, Chammas N. Myxedema ascites with high CA-125: case and a review of literature. World J Hepatol. 2013; 5:86-89.

8. Hataya $\mathrm{Y}$, Akamizu T, Kanamoto N, Moriyama K, Shimatsu A, Nakao K: A case of subclinical hypothyroidism developing marked pleural effusions and peripheral edema with elevated vascular endothelial growth factor. Endocr J. 2007; 54(4):577-84.

9. McDonough $\mathrm{CH}$, Lee $\mathrm{L}$, de Beur SJ, Arai S, Vogelsang GB. Myxedema ascites in the posttransplant setting: Case report. Am J Hematol. 2002; 71:216-8.

10. De Feudis L, Scudieri M, Orlando D, Traisci G. Ascites as preeminent manifestation of primary hypothyroidism. Clinical case. Ann Ital Med Int. 1999; 14:294-7.

11. Otero Bedoya J, Landeira G, Corino M, Tamashiro A, Fassio E. Ascitis due to hypothyroidism in a patient with alcoholic cirrhosis. Acta Gastroenterol Latinoam. 2001; 31:77-81. 